\title{
Review
}

\section{Human prostate cancer heterotransplants: a review on this experimental model}

\author{
Lluis A. Lopez-Barcons \\ Stanley S. Scott Cancer Center, Louisiana State University, Health Sciences Center, New Orleans, LA 70112, USA
}

\begin{abstract}
A common model used for preclinical research was in vitro human tumor cell culture. An alternative model was the direct implantation of a unique patient's tumor biopsy specimens into immunodeficient host mice. Published data from PubMed (http://www.ncbi.nlm.nih.gov) and Current Contents Connect databases (http://thomsonreuters.com/ products_services/science/science_products/a-z/current_contents_connect) were reviewed. Prostate cancer (PCa) heterotransplantation was evaluated using histopathology, morphology, cell differentiation, DNA content, tumor marker expression, metastases, tumor kinetics, tumor take rate and tumor vasculature in the first tumor heterotransplant. The heterotransplanted tumor retained the biological properties of the original tumor, such as morphology, degree of differentiation, pathology, secretory activity, expression of tumor markers and human vasculature. Human PCa heterotransplants have considerable experimental advantages over cell culture following xenotransplantation.
\end{abstract}

Asian Journal of Andrology (2010) 12: 509-518. doi: 10.1038/aja.2010.17; published online 5 April 2010.

Keywords: cancer, experimental model, heterotransplant, nude mice, prostate, xenotransplant

\section{Introduction}

Developing therapies for prostate cancer $(\mathrm{PCa})$ require accurate tumor models relevant to human $\mathrm{PCa}$. There are few animal models for PCa available, as the only other mammals, besides humans, that develop PCa are primates and dogs [1]. Both animal models

Correspondence to: Dr Lluis A Lopez-Barcons, Stanley S. Scott Cancer Center, Louisiana State University, Health Sciences Center, 533 Bolivar Street, New Orleans, LA 70112, USA. Fax:+1-504-568-6888_E-mail: lalb93@gmail.com Present address: Department of Radiation Oncology, Emory University School of Medicine and Winship Cancer Institute, 1365C Clifton Road, Atlanta, GA 30322, USA.

Fax: +1-404-778-1909 E-mail: llopezb@emory.edu

Received: 18 November 2009 Revised: 13 January 2010

Accepted: 16 January $2010 \quad$ Published online: 5 April 2010 are very expensive and tight regulatory constraints limit their availability. Other available tumor models include rodent prostate tumors, but the extrapolation of results obtained from these tumors is limited by their non-human origin, thereby restricting their direct applicability to human disease. The use of xenografts in mice as a preclinical PCa model is reasonably inexpensive, provides rapid experimental data and is largely free of regulatory constraints. In these models, in vitro cultured human PCa cells (most commonly PC-3, DU$145, \mathrm{LNCaP}$ or a cell line derived from one of these three) are implanted into immunosuppressed mice. The human origin of these cells therefore more directly represents the human disease. However, cell lines for culture have been developed from a limited sample of PCa biopsies, and all three commonly used cell lines were derived from PCa primary tumors and its metastases in the late 1970s to early 1980s.

The prostate is a complex organ system with dis- 
tinct anatomical zones and heterogeneous cells in the epithelium, including epithelial cells (luminal and basal) and neuroendocrine cells, and, in the stroma, smooth muscle cells and fibroblasts, along with nerves and the basement membrane. The coordinated activity of all these cells is required for normal organ function, and is affected by tumor development. The stromal cells are especially important in the development of PCa tumors; they often supply tumor cells with the signals and nutrients they need to proliferate and expand [2]. The co-implantation of human tumor cells with human stromal cells results in tumors with a more human-like structure. These interactions between different cell populations are often lost in cell cultureinduced xenografts, because the different cell types are not present in the transplant. Therefore, these in vitro cultured cell lines suffer from the absence of tumorstromal interactions, which induces a distinctly different cell morphology from that found in the tissue of origin. Generally, xenografts derived from cultured cells have a more homogeneous and undifferentiated histology.

There are an increasing number of published reports demonstrating that developing cell lines from human cancers sometimes results in distinct and irreversible loss of important biological properties. Some tumor cell subpopulations might not contain the genetic aberrations that enable adaptation to artificial cell culture. In glioblastoma multiforme, serial human tumor heterotransplantation selected for epidermal growth factor receptor (EGFR) amplifications that reflect the high incidence of EGFR amplification found in patients, whereas in vitro glioblastoma cell cultures selected against this gene alteration [3]. In addition, the genomic profile of glioblastoma cell cultures in vitro deviated substantially from the original tumor profiles [4]. Additional evidence showed that the Sonic hedgehog pathway was suppressed in medulloblastoma cell cultures in vitro, and was not restored when the cells were transplanted into nude mice [5]. Similarly, in small-cell neuroendocrine lung carcinoma, the gene expression pattern changed irreversibly when cell lines were cultured in vitro from the original tumors. The expression of a large number of such genes was not restored when the derivative cell line was returned to growth in vivo as a xenograft [6]. Finally, in pediatric tumors such as neuroblastoma, rhabdomyosarcoma and Ewing's sarcoma, the human tumor xenografts have substantial transcriptional similarity to their respective primary tumor types, compared with cell lines in culture. Importantly, a higher level of similarity exists between the xenograft and the primary tumor not only for a particular gene target or targets, but also for specific genes in specific biological functions [7]. In all these cases, the original tumor cell properties are not restored when the conventional cell lines are grown as xenografts, resulting in selection for certain cell subtypes that are not relevant to the malignant disease, and resulting in tumors that no longer represent the phenotype of tumor cells in patients.

Comparison of the gene expression patterns in human $\mathrm{PCa}$ cell lines in vitro with the overall gene expression patterns of human tissues yielded somewhat conflicting results $[8,9]$. One study revealed highly divergent gene expression patterns between cells grown in vitro and the human tumor specimens [9], while another study found that the majority of the genes up- or down-regulated were consistent between the two groups [10]. In the second study, the researchers used five distinct human prostate carcinoma cell lines derived from a highly tumorigenic orthotopic xenograft with intermediate to very high metastatic potential, itself derived from two parental cell lines (LNCaP and PC-3). These cells were subjected to one to five additional cycles of experimental tumor progression in vivo. The changes in transcript expression levels were compared with clinical specimens ( $88 \%$ clinically stages $\mathrm{T} 1-\mathrm{T} 2 \mathrm{a} ; 92 \%$ pathologically less than or equal to stage T3a). This review is focused on studying the initial heterotransplantation (first passage in vivo) of human PCa tumors on host mice. For a detailed study on serial heterotransplantation (serial passaging in vivo) of human $\mathrm{PCa}$ tumors on host mice, readers are referred to Lopez-Barcons [11].

\section{Materials and methods}

The information for this review was compiled by searching the PubMed (http://www.ncbi.nlm.nih. gov) and Current Contents Connect databases (http:// thomsonreuters.com/products_services/science/science products/a-z/current_contents_connect) for articles published until September 2009. Electronic earlyrelease publications were also included. Only articles published in English were considered. The search terms used included 'explant', 'heterotransplant', 'heterotransplantation', 'human xenograft', 'nude mice', 'prostate cancer', 'transplantation', 'tumor line', 'tumor models', 'xenograft' and 'xenotransplantant' and its 
combinations. Full articles were obtained and references were checked for additional material, as appropriate.

\section{Human tumors heterotransplantation at first passage into immunosuppressed mice: similarities with the patient tumor of origin}

In the text, the standard heterotransplant implantation site is the subcutaneous space (SC) of the host mouse. When other implantation sites have been used, the location will be cited specifically.

\subsection{Histological analysis}

Primary reports from Gittes et al. $[12,13]$ described the development of squamous metaplasia and interstitial fibrosis in PCa heterotransplants. The implanted tumor was clearly modified from the original carcinoma in situ during its time in the host mouse. However, subsequent reports showed that, in general, in the first heterotransplantation of the original tumor, the fragment growing in the SC space retains the original morphology; meanwhile, histological and cytological analysis revealed as similar or identical to the tumor in situ. Therefore, the heterotransplanted tumor, in the first passage, always showed a histopathological pattern typical of human prostate carcinoma. This fidelity has been demonstrated for well-differentiated, moderately differentiated and poorly differentiated carcinomas, as well as metastatic tumors that are moderately to poorly differentiated [14-28]. Similar results were obtained with poorly differentiated primary carcinomas when the implantation site was the renal subcapsule [29]. Remarkably, differentiated tumors do not become anaplastic but remain differentiated once heterotransplanted into the host mice [30, 31]. In addition, the heterotransplanted tumors have a Gleason score identical to the original biopsy [27, 32]. However, the heterotransplants possess little stroma that, histologically, seems derived from the host mouse [18]. Notably, the histology of the human prostate tumor is preserved in the heterotransplant, even when the tissue is cryopreserved before transplantation [27, 32]. These results have been found regardless of the mouse strain used (athymic nude, severe combined immunosuppressed mice [scid], or hpg/hpg or hpg/scid mice [gonadal steroid-deficient mice]) [33], the coinjection of tumor tissue with Matrigel (BectonDickinson, Franklin Lakes, NJ, USA), or the use of intact or orchiectomized mice treated with androgen supplements. Matrigel is an extracellular matrix gel composed of type IV procollagen, laminin and heparan sulfate proteoglycan obtained from the EngelbrethHolm-Schwarm mouse sarcoma first described by Kleinman et al. [34]. On the other hand, sometimes the implanted tumor developed minor histological differences such as stromal tissue inflammation, squamous and transitional metaplasia, or production of keratin at the site of implantation $[32,35]$.

\subsection{DNA content}

The heterotransplanted tumors in the first passage obtained from a moderately differentiated adenocarcinoma by Hoehn et al. $[18,36]$ (named PC82 ), and the heterotransplanted tumor obtained in 1984 from a poorly to moderately differentiated lymph node metastasis (named PC-EW) have tetraploid DNA content with an additional small diploid subline, possibly from host mice cells from blood and stroma. In contrast, van Weerden et al. [37] determined that the heterotransplanted tumors PC-295, PC-310, PC324, PC-329, PC-339 and PC-346 were all diploid. However, the PC-295 appears to have a small population of tetraploid cells; meanwhile, the PC374 heterotransplant is a tetraploid tumor. Six allelic imbalances (8p21-p22, 16q24, 10q22-q23, 13q12-q13, $17 \mathrm{q} 21,18 \mathrm{q} 21$ ) were found in the original patient specimen used for the PAC120 heterotransplant; all six were found in the PAC-120 heterotransplant [25].

\subsection{Marker expression}

Initial reports stated that the original tumor and its corresponding heterotransplanted tumor in mice expressed prostate acid phosphatase (PAP) $[12,13,15$, $18,19,22]$ or small amounts of tartrate-inhibitable acid phosphatase [35] (Table 1). The expression of prostate serum antigen (PSA) in the glandular epithelium is comparable between the primary tumor and the matching histological sections from the heterotransplanted tumor $[22,28,32,38]$, as well as the high serum PSA concentration in the patient and heterotransplant PSA expression [39]. Interestingly, serum PSA concentration correlated linearly with heterotransplant tumor volume, as shown by the increase in serum PSA concentration in the patient while the liver metastasis progressed. In addition, both the original primary tumor and histological sections from the heterotransplanted tumor have identical hexosaminidase expression [22]. When the primary tumor was implanted into the mice subrenal capsule, 
Table 1. Reported human prostate cancer heterotransplants in vivo.

\begin{tabular}{|c|c|c|c|c|c|c|c|c|c|c|}
\hline Name model & Origin & $\begin{array}{l}\text { Hormonal } \\
\text { status of } \\
\text { host mice }\end{array}$ & $\begin{array}{l}\text { Androgen } \\
\text { responsive }\end{array}$ & $\mathrm{AR}$ & PAP & PSA & $\mathrm{p} 53 / \mathrm{bcl}-2$ & $\begin{array}{c}\text { Lag } \\
\text { phase } \\
\text { (month) }\end{array}$ & Td (days) & Reference \\
\hline$\overline{\mathrm{BM}-18}$ & Bone metastases & 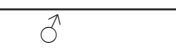 & + & + & & + & & & & [28] \\
\hline CWR21 & $\begin{array}{l}\text { PPT stage D, } \\
\text { osseous metastases }\end{array}$ & $\delta+T$ & & & & & & $8-11$ & & [22] \\
\hline CWR22 & PPT stage $\mathrm{C}$ & $\hat{\sigma}+\mathrm{T}$ & $+/$ & $\mathrm{H} 874 \mathrm{Y}$ & & + & & $2-5$ & & [22] \\
\hline CWR22R & CWR22 & $\hat{\sigma}+\mathrm{T}$ & - & & & & & & & [47] \\
\hline CWR31 & $\begin{array}{l}\text { PPT stage D, } \\
\text { osseous metastases }\end{array}$ & $\hat{\sigma}+\mathrm{T}$ & & & & & & $2-4$ & & [23] \\
\hline CWR91 & $\begin{array}{l}\text { PPT stage D, } \\
\text { osseous metastases }\end{array}$ & $\hat{\sigma}+\mathrm{T}$ & & & & & & $1.5-5$ & & {$[23]$} \\
\hline EB42 & PPT & $\hat{o}+\mathrm{T}$ & & & & & & & & {$[30]$} \\
\hline EB54 & PPT & $\hat{o}+\mathrm{T}$ & & & & & & & & {$[30]$} \\
\hline EB57 & PPT & $\hat{0}$ & & & & & & & & {$[30]$} \\
\hline HONDA & Testis metastases & $\hat{0}$ & + & + & & + & + & & 9.5 & [48] \\
\hline $\mathrm{KUCaP}$ & Liver metastases & $\hat{0}$ & muts & $\begin{array}{c}+ \\
\text { tated } \mathrm{W} 7\end{array}$ & $1 \mathrm{C}$ & & & & & [39] \\
\hline LAPC-3 & TURP & $\hat{0}$ & + & $\mathrm{Wt}$ & & + & & 10 & & [43] \\
\hline LAPC-4 & LN & $\hat{o}$ & + & $\mathrm{Wt}$ & & + & & 3 & & {$[43]$} \\
\hline $\mathrm{LuCaP} 23.1$ & $\mathrm{LN}$ & $\hat{0}$ & + & & & + & & $1-1.5$ & $11-20$ & [41] \\
\hline $\mathrm{LuCaP} 23.8$ & $\mathrm{LN}$ & $\hat{0}$ & + & & & + & & $1-1.5$ & 15 & [41] \\
\hline $\mathrm{LuCaP} 23.12$ & Liver metastases & $\hat{0}$ & + & & & + & & $1-1.5$ & 21 & [41] \\
\hline LuCaP 35 & LN & 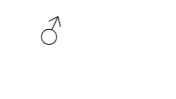 & & $\mathrm{Wt}$ & & + & & $\begin{array}{l}21-30 d^{\mathrm{a}} \\
21-73 \mathrm{~d}^{\mathrm{c}}\end{array}$ & $\begin{array}{r}10.3 \pm 0.6^{\mathrm{b}} \\
9.6 \pm 1.3^{\mathrm{d}}\end{array}$ & [49] \\
\hline $\mathrm{LuCaP} 35 \mathrm{~V}$ & LuCaP 35 & 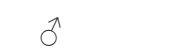 & - & $\mathrm{Wt}$ & & + & & $21-70 d^{c}$ & $16.6 \pm 1.0^{\mathrm{c}}$ & [49] \\
\hline $\mathrm{LuCaP58}$ & $\mathrm{LN}$ & $\hat{0}$ & & + & & + & & & & {$[50]$} \\
\hline $\mathrm{LuCaP73}$ & Pelvic mass & $\hat{\sigma}$ & & + & & + & & & & {$[50]$} \\
\hline M27/78 & & $\hat{o}+\mathrm{T}+\mathrm{E}$ & & & & & & & 14.3 & [16] \\
\hline M29/78 & & $\hat{o}+\mathrm{T}+\mathrm{E}$ & & & & & & & 11.9 & [16] \\
\hline PAC- 120 & Primary recurrence & $\hat{\sigma}$ & + & & + & - & Mutated/- & & & [25] \\
\hline PC-82 & PPT pT $3 \mathrm{pN}_{0} \mathrm{M}_{0} / \mathrm{G}_{2}$ & $\hat{\delta}+\mathrm{T}$ & + & + & + & + & -/-ADCP + & $27(10-71)$ & d $18(9-27)$ & {$[18]$} \\
\hline PC-133 & Bone metastases & & - & - & - & - & ADCP - & & 10 & {$[51]$} \\
\hline PC-135 & PPT & $\widehat{\sigma}+\mathrm{T}$ & - & - & - & - & $\begin{array}{l}-/- \text { in }{ }_{+} \\
\mathrm{ADCP}_{-}\end{array}$ & & 15 & {$[51]$} \\
\hline PC-295 & LN & $\hat{\jmath}+\mathrm{T}$ & + & $\mathrm{Wt}$ & ++ & + & $-1-$ & $2-3$ & 18 & {$[37]$} \\
\hline PC-310 & PPT & $\hat{o}+$ DHT & + & $\mathrm{Wt}$ & ++ & + & $-/+$ & 4 & 13 & {$[37]$} \\
\hline PC-324 & TURP & $\hat{o}+\mathrm{T}$ & - & - & \pm & - & $+/+$ & $1-2$ & 10 & [37] \\
\hline PC-329 & PPT & o & + & $\mathrm{Wt}$ & + & + & $-1-$ & $4-5$ & & [37] \\
\hline PC-339 & TURP & $\hat{\jmath}+\mathrm{DHT}$ & - & - & - & - & $+/ \pm$ & $1-2$ & 20 & {$[37]$} \\
\hline PC-346 & TURP & $\hat{\sigma}$ & + & $\mathrm{Wt}$ & \pm & + & $-1-$ & $1-2$ & 7 & [52] \\
\hline PC-346B & PC-346 & $\hat{\sigma}$ & + & $\mathrm{Wt}$ & & + & & $19-62 d$ & $12.1 \pm 2.6$ & {$[52]$} \\
\hline PC-346BI & PC-346 & & - & $\mathrm{Wt}$ & & + & & & & {$[52]$} \\
\hline PC-346I & PC-346 & & - & T877A & & + & & & & {$[52]$} \\
\hline PC-346P & PC-346 & $\hat{0}$ & + & $\mathrm{Wt}$ & & + & & $24-45 d$ & $8.1 \pm 0.5$ & {$[52]$} \\
\hline PC-346 SIcas & PC-346 & & - & $\mathrm{Wt}$ & & + & & & & [52] \\
\hline PC-374 & SSM & $\hat{\sigma}$ & - & $\mathrm{Wt}$ & ++ & + & $-1-$ & 2 & 12 & [52] \\
\hline PCa1 & PPT & $\hat{\sigma}+\mathrm{T}$ & & + & & + & & & 7 & [29] \\
\hline
\end{tabular}


Table 1. Reported human prostate cancer heterotransplants in vivo (continued).

\begin{tabular}{|c|c|c|c|c|c|c|c|c|c|c|}
\hline Name model & Origin & $\begin{array}{c}\text { Hormonal } \\
\text { status of } \\
\text { host mice }\end{array}$ & $\begin{array}{l}\text { Androgen } \\
\text { responsive }\end{array}$ & $\mathrm{AR}$ & PAP & PSA & $\mathrm{p} 53 / \mathrm{bcl}-2$ & $\begin{array}{c}\text { Lag } \\
\text { phase } \\
\text { (month) }\end{array}$ & Td (days) & Reference \\
\hline PCa1-met & $\mathrm{LN}$ & $\delta+T$ & & + & & + & & & & [29] \\
\hline PC-EG & TURP & $\hat{\sigma}+\mathrm{T}$ & + & & & & & & 15 & [21] \\
\hline PC-EW & $\begin{array}{c}\mathrm{LN} \\
\mathrm{cT} 3 \mathrm{pN}_{2} \mathrm{M}_{0} / \mathrm{G}_{3}\end{array}$ & $\hat{\sigma}+\mathrm{T}$ & + & + & + & + & $\mathrm{ADCP}+$ & & 10 & [36] \\
\hline Pro-1 & & $\widehat{0}$ & - & & & & & & & {$[53]$} \\
\hline R198 & PPT & $\hat{0}+\mathrm{T}$ & $50 \%$ & & & + & & & & [35] \\
\hline TEN/12 & & 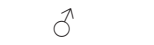 & + & + & + & + & & & & [20] \\
\hline TEN12C & TEN12 & $\hat{\sigma}$ & & + & & + & & & & {$[54]$} \\
\hline TEN12F & TEN12 & $\hat{\sigma}$ & & + & & + & & & & [54] \\
\hline TEN12FM & TEN12 & $\hat{\sigma}$ & & + & & + & & & & {$[54]$} \\
\hline Unnamed & Dura & $\hat{o}$ & & & & & & & 10 & [38] \\
\hline Unnamed & Dura2 & $\hat{0}$ & & & & & & & 8 & [38] \\
\hline Unnamed & Femur & $\hat{\sigma}$ & & & & & & & 16 & [38] \\
\hline Unnamed & Liver & $\hat{\sigma}$ & & & & & & & 7 & [38] \\
\hline Unnamed & Rib & 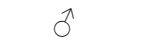 & & & & & & & 30 & [38] \\
\hline Unnamed & Skull & $\hat{0}$ & & & & & & & 12 & {$[38]$} \\
\hline Unnamed & Sphenoid & $\hat{\sigma}$ & & & & & & & & {$[38]$} \\
\hline Unnamed & Spine & $\hat{0}$ & & & & & & & & {$[38]$} \\
\hline
\end{tabular}

Abbreviations: ADCP, adenosine deaminase complexing protein; AR, androgen receptor; d, days; DHT, $5 \alpha$-dihydrotestosterone; E, estradiol; LN, lymph node metastases; PAP, prostate acid phosphatase; PPT, primary prostate tumor; PSA, prostate serum antigen; SSM, scrotal skin metastases; T, testosterone; Td, tumor-doubling time; TURP, transurethral resection of the prostate; Wt, wild type.

${ }^{\mathrm{a}}$ Intact mice; ${ }^{\mathrm{b}}$ First mouse passage in Balb/c athymic nude mouse; ${ }^{\mathrm{c}}$ Orchiectomized mice; ${ }^{\mathrm{d}}$ When patient specimen is taken and implanted into host mice.

strong PSA expression was found in the heterotransplanted tumor, matching the original specimen [29].

\subsection{Hormone dependence}

The study of hormonal dependence in the first passage of the heterotransplantated PC tumors was based entirely on its effect on the tumor take rate. In the reviewed literature, there is no study found examining androgen receptor (AR) expression or changes in the first heterotransplant at the cytological, histological or molecular level caused by host hormone deprivation. In contrast, these changes have been widely studied using tumor heterotransplants at a higher passage number (Table 1). The hormonal dependence, tumor status and hormone marker expression are discussed in detail in another review [11].

\subsection{Metastases}

Hoehn et al. [18] reported that, for the PC-82 tumor heterotransplant, no metastases were found in any organ on autopsy in the host mice. Similar results were reported for the PC-EW heterotransplanted tumors [36]. In addition, Wang et al. [29] did not find any metastases from their heterotransplanted tumors, a low-grade $\mathrm{PCa}$, even when implanting the $\mathrm{PCa}$ tumor fragments orthotopically in the prostate. Complete information regarding Dr Y Wang's xenografts can be found in http://www.bccrc.ca/ce/people_Ywang.html. On the other hand, Lubaroff et al. [33] described the development of metastases to the lung after implantation of a prostate adenocarcinoma in scid hpg/-(gonadal steroid deficient) mice bearing $5 \alpha$-dihydrotestosterone implants. Histologically, the metastases presented as a gland formation but without the stroma seen in the primary tumor. Similarly, the CWR 21 heterotransplanted tumor develops lung metastases when coimplanted with Matrigel in nude mice treated with testosterone (T) pellets. Interestingly, the PSA concentration found in the metastases was high. Unfortunately, the donor patient of the tumor was diagnosed with pulmonary metastases at 
the time of autopsy [23]. In addition, de Pinieux et al. [25] detected micrometastases in the lungs of mice bearing a PC-120 heterotransplant. Their presence was detected by using the reverse transcriptase polymerase chain reaction to detect expression of the PSA, EGFR-2 and homeobox B9 genes. In this case, the donor patient of the tumor was diagnosed with multiple lung metastases when admitted to the hospital with dyspnea symptoms [25].

\subsection{Tumor kinetics}

Quantitative analysis of original tumors (five Gleason score 6 carcinomas) and the corresponding first heterotransplanted tumors growing after 1 month in the host mice revealed that the difference in the number of proliferating cells was not remarkable in two of five tumor tissues studied, and neither was the apoptotic index analysis in four of the five cases studied [32]. Similar conclusions were obtained by Wang et al. [29] when comparing the original tumor with a sample from a tumor fragment heterotransplanted into the renal subcapsule after 3 months. The proliferation rate for the patient's tumor in situ was $2.49 \% \pm 0.40 \%$ and $2.28 \% \pm 0.48 \%$ for the tumor heterotransplanted into the mice.

\subsection{Tumor take rate}

Researchers working in this field consider human specimen heterotransplantation successful when viable tumor tissue is found after histological examination of the heterotransplanted tumor in the host mice. However, realistically, the successfully heterotransplanted mice from one patient are considered only one success, independent of the number of mice successfully transplanted with the same patient specimen (Table 1). Initial studies reported encouraging tumor take rates of $50 \%$ (4 of 8 ) [12,13] and $100 \%$ (2 of 2 ) [14] for tumors heterotransplanted in athymic nude mice supplemented or not with T-pellets, respectively. However, more discouraging take rates of $15.8 \%$ were obtained by Schroeder et al. [30], 3\% (3 of 100) by Reid et al. [31] and 1\% (1 of 100) by Reid et al. [35] for tumors heterotransplanted in athymic nude mice supplemented with T-pellets. A take rate of $11 \%(2$ of 17) was obtained for tumors heterotransplanted into the same mice strain, but into mice not receiving hormone supplements [40]. Concerned by these low take rates, Jones et al. [16] studied the tumor take rate as a function of tumor grade and mice strain used as a host. A discouraging take rate of $0 \%(0$ of 14$)$ was obtained for well-differentiated carcinomas and moderately differentiated carcinomas ( 0 of 24$)$ and only a $2 \%$ take rate was obtained with poorly differentiated carcinomas ( 2 of 33 ). Interestingly, the authors did not find any difference in take rate when using immunosuppressed nude mice or immunodeprived mice. A similar take rate of $10 \%$ (1 of 10$)$ was obtained by van Weerden et al. [37] when pelvic lymph node metastatic tumors were heterotransplanted into athymic nude mice supplemented with T-pellets. On the other hand, Ellis et al. [41] reported a take rate of $100 \%$ (3 of 3) when two lymph nodes and one liver metastases were heterotransplanted into intact athymic nude mice. Taken together, these studies show that the high tumor take rate is not related to the tumor pathological grade when using athymic nude mice as the host mice.

More discouraging take rates of $0 \%$ ( 0 of 4 and 0 of 24) were obtained by van Weerden et al. [37] when heterotransplanted primary adenocarcinomas were obtained or not, respectively, by the transurethral resection procedure (TURP) in athymic nude mice being supplemented with T-pellets. As expected, the initial take rate was $0 \%$ ( 0 of 63 ) for tumors heterotransplanted in athymic nude mice that were supplemented with T-pellets [17]. However, when host mice were treated with sheep anti-mouse interferon serum, the globulin fraction, or rabbit anti-mouse serum, the take rate, surprisingly, rose to $100 \%$ ( 2 of 2, 4 of 4 and 5 of 5 ) for each treatment, respectively [17]. This result demonstrates that athymic nude mice generate a limited, but definite, immunological response to the implanted prostatic human tumors, resulting in a high tumor rejection rate.

As a result, some authors decided to use more severe immunodeficient mice strains like the NMRI nude mice or the CB17-NOD scid mice as tumor hosts. When NMRI athymic nude mice (a specific strain of mice that may have reduced natural killer cell activity) were used and were supplemented with T-pellets, the tumor take rate was $28 \%$ ( 2 of 7) [37]. However, when this mice strain was used for tumor heterotransplantation without androgen supplementation, the take rate was $0 \%$ [42]. The same authors reported a $50 \%$ take rate (3 of 6) when the heterotransplanted tumors were obtained by the TURP surgical procedure. When the more severely immunosuppressed mouse strain CB17-NOD scid was used as the host, the take rates were $60 \%$ (3 of 5 ) and $57 \%$ (8 of 14) [33, 38]. Using the same strain but providing the mice with T-pellet supplements, the tumor take rate was $58.1 \%$ (50 of 
86) [29]. Subsequently, Wang et al. [29] studied the effect of the tumor implantation site on the take rate using the same mice strain but with orchiectomized and hormonally supplemented mice. The take rates were $93.4 \%$ (114 of 122), 58.1\% (50 of 86) and 71.9\% (41 of 57) for heterotransplantation in the subrenal capsule, in the sc space and orthotopically in the prostate, respectively. Finally, another strategy was used by another group to improve the tumor take rate: the patient's tumor tissue was combined with Matrigel (Becton-Dickinson), resulting in a take rate of $60 \%$ (6 of 10) using athymic nude mice not given T-pellet supplements [22]. When mice from the same strain were used as hosts but T-supplemented, the take rate was $20 \%$ (4 of 20 ), $100 \%$ (5 of 5) and $92.7 \%$ (41 of $42)$ in three separate reports, respectively [23, 26, 33]. When scid mice were used as tumor hosts but not given hormone supplements, the take rate was $75 \%$ [43]. In conclusion, a high tumor take rate for the heterotransplantation of prostate carcinomas is obtained when the original tumor tissue is combined with Matrigel (Becton-Dickinson) and implanted into host mice that are not severely immunosuppressed. When severely immunosuppressed mice are used as the host, a successful heterotransplantation may result when the specimen is implanted alone. In both cases, hormonal supplementation with T-pellets is advantageous. When the original tissue was cryopreserved before implantation, the tumor take rate was reduced compared with heterotransplants implanted from fresh tissue [27].

\subsection{Vasculature}

The PCa heterotransplanted tumors combined with Matrigel (Becton-Dickinson) were viable and well vascularized after 1 month of implantation, as seen by the presence of small vessels of human origin with red blood cells inside. In the original tumor, and in the heterotransplanted tumor, the vasculature was found both adjacent to glands and distributed through the stroma [26, 32]. More specifically, the average number of vessels per field, or mean vessel density (MVD), was increased remarkably in the PCa heterotransplanted tumors compared with the original tumor as determined by staining with human anti-CD31 antibody (2.0-fold), the human anti-CD34 antibody (2.1-fold) and human anti-vWF-positive antibody (4.1fold). Correspondingly, the average number of vessels with at least one proliferating endothelial cell (EC) per field (proliferative MVD) increased fivefold in the heterotransplanted PCa tumors compared with the original tumor in situ. A twofold increase in the MVD of small-to-medium-diameter vessels was observed in the heterotransplanted tumors compared with the original carcinomas. Likewise, the mean vessel area and the mean vessel perimeter were evidently reduced (1.7-fold) in the heterotransplanted tumors compared with the corresponding original specimens. The increased number of small vessels in the heterotransplanted tumors correlates with angiogenesis, in which new vessels growing from existing ones are smaller in diameter and contain proliferative EC. Interestingly, after heterotransplantation, the percentage of human vessels in the viable heterotransplants was $79.3 \% \pm 4.8 \%[26]$.

\section{Heterotransplantation quality control}

The successful use of human prostate heterotransplants requires quality control, for both the immunodeficient host and the implanted human tissue. First, the microbial health status of host mice is critical. Second, karyotyping and histopathological evaluation of the heterotransplanted tumor are necessary to confirm that the resultant tumors are benign or malignant human prostate carcinomas. Such measures will avoid overgrowth of the heterotransplant by murine cells that express the B-cell differentiation antigens CD19, CD20 and CD22 [43, 44]. A tumor tissue stockpile is highly desirable to create a repository of early passages (within 5-10 passages) of well-characterized heterotransplants at the genetic and biochemical level. This should include chromosomal analysis as well as gene expression data on a minimal subset of prostate marker genes such as AR and PSA. To determine what to heterotransplant, the National Cancer Institute (NCI) has an outstanding guide entitled 'Best Practices for Biospecimen Resources' (2007) that accurately answers the questions previously stated [45]. The limitations in the use of human heterotransplants have been discussed thoroughly in another review [46].

Unfortunately, there are few in vivo models of $\mathrm{PCa}$ that reflect the different stages of disease progression, which means that experimentation does not reflect the complexity and diversity of human $\mathrm{PCa}$ tumors encountered by clinicians. A successful $\mathrm{PCa}$ heterotransplant model must have two important characteristics. First, the accuracy of the model must be known; the extent to which the tumor heterotransplanted 
initially into the host mouse resembles the original tumor and, thereby, reflects the original PCa is critical. Second, the model has to represent the disease found in humans at all stages of progression. As demonstrated, there is sufficient knowledge acquired during the past 30 years on human prostate tumor heterotransplantation to understand how human tumors maintain their integrity after first transplantation into a mouse, or how they change as a result of the interaction with host mice cells.

\section{Conclusion}

The PCa tumors of the first heterotransplant into host mice retain the important biological properties present in the original primary tumor, such as morphology, pathology and functional biochemistry, including active secretion and the expression of important tumor markers. Importantly, the human tumor architecture is preserved, allowing the important stromal cell-epithelial cell crosstalk and the presence of human vasculature. The model can represent the disease, including the various stages of clinical PCa. The heterotransplant model permits the growth of human prostatic tumors with varying degrees of differentiation allowing the testing of new drugs and new therapeutic regimens for the treatment of $\mathrm{PCa}$ at different stages. This model has wide applicability to the study of human PCa angiogenesis in a human microvascular environment and provides an excellent system to test new anti-angiogenic therapies. In addition, the human tumor heterotransplant model may provide more realistic data from proteomics and pharmacogenomics. Establishing the heterotransplant PCa model is a remarkable tool to study prostate diseases.

\section{References}

1 De Marzo AM, Coffey DS, Nelson WG. New concepts in tissue specificity for prostate cancer and benign prostatic hyperplasia. Urology 1999; 53: 29-39.

2 Taylor RA, Risbridger GP. Prostatic tumor stroma: a key player in cancer progression. Curr Cancer Drug Targets 2008; 8: 490-7.

3 Pandita A, Aldape KD, Zadeh G, Guha A, James CD. Contrasting in vivo and in vitro fates of glioblastoma cell subpopulations with amplifies EGFR. Genes Chromosomes Cancer 2004; 39: 29-36.
4 De Witt Hamer PC, van Tilborg AA, Eijk PP, Sminia P, Troost $\mathrm{D}$, et al. The genomic profile of human malignant glioma is altered early in primary cell culture and preserved in sphenoids. Oncogene 2008; 27: 2091-6.

5 Sasai K, Romer JT, Lee Y, Finkelstein D, Fuller C, et al. Shh pathway activity is down-regulated in cultured medulloblastoma cells: implications for preclinical studies. Cancer Res 2006; 66: 4215-22.

6 Daniel VC, Marchionni L, Hierman JS, Rhodes JT, Devereux WT, et al. A primary xenograft model of small-cell lung cancer reveals irreversible changes in gene expression imposed by culture in vitro.Cancer Res 2009; 69: 3364-73.

7 Whiteford CC, Bilke S, Gree BT, Chen Q, Braunschweig TA, et al. Credentialing preclinical pediatric xenograft models using gene expression and tissue microarray analysis. Cancer Res 2007; 67: 32-40.

8 Dhanasekaran SM, Barrette TR, Ghosh D, Shah R, Varambally $\mathrm{S}$, et al. Delineation of prognostic biomarkers in prostate cancer. Nature 2001; 412: 822-6.

9 Welsh JB, Sapinoso LM, Su AI, Kern SG, Wang-Rodriguez $\mathrm{J}$, et al. Analysis of gene expression identifies candidate markers and pharmacological targets in prostate cancer. Cancer Res 2001; 61: 5974-8.

10 Glinsky GV, Krones-Herzig A, Glinskii AB, Gebauer G. Microarray analysis of xenograft-derived cancer cell lines representing multiple experimental models of human prostate cancer. Mol Carcinogenesis 2003; 37: 209-21.

11 Lopez-Barcons LA. Serially passaged human prostate cancer heterotransplants as an experimental model. J Cell Mol Med 2009, Oct 29 [Epub ahead of print] PMID: 19874422 .

12 Gittes RF, McLaughlin AP, Brooks JD. Discussion of etiology and prevention of prostatic cancer. Cancer Chemother Rep 1975; 59: 73-87.

13 Gittes RF. The nude mouse-its use as tumor-bearing model of the prostate. In: Murphy GP, editor. Models for Prostate Cancer. New York: Alan R. Liss, Inc.; 1980. p31-7.

14 Shimosato Y, Kameya T, Nagai K, Hirohashi S, Koide S, et al. Transplantation of human tumor in nude mice. J Natl Cancer Inst 1976; 56: 1251-66.

15 Williams G, Ghanadian R, Castro JE. The growth and viability of human prostatic tissue maintained in immunosuppressed mice. Clin Oncol 1978; 4: 347-51.

16 Jones MA, Williams G, Davies AJS. Value of xenografts in the investigation of prostatic function: preliminary communication. J Royal Soc Med 1980; 73: 708-12.

17 Reid LM, Minato N, Gresser I, Holland J, Kadish A, et al. Influence of anti-mouse interferon serum on the growth and metastasis of tumor cells persistently infected with virus and of human prostatic tumors in athymic nude mice. Proc Natl Acad Sci USA 1981; 78: 1171-5.

18 Hoehn W, Schroeder FH, Riemann FJ, Joebsis AC, Hermanek P. Human prostatic adenocarcinoma some characteristic of a serially transplantable line in nude mice PC82. Prostate 1980; 1: 95-104.

19 Graham SD, Poulton SH, Linder J, Woodard MB, Lyles $\mathrm{KW}$, et al. Establishment of a long-term adenocarcinoma of 
the prostate cell line in the nude mouse. Prostate 1985; 7 : 369-76.

20 Harper ME, Sibley PEC, Rowlands A, Buttifant L, Beacock $\mathrm{C}$, et al. Hormonal modulation of the growth of a new transplantable prostatic cell line in athymic nude mice. Urol Res 1986; 14: 156.

21 Csapo Z, Brand K, Walther R, Fokas K. Comparative experimental study of the serum prostate specific antigen and prostatic acid phosphatase in serially transplantable human prostatic carcinoma lines in nude mice. J Urol 1988; 140: $1032-8$.

22 Pretlow TG, Delmoro CM, Dilley GG, Spadafora CG, Pretlow TP. Transplantation of human prostatic carcinoma into nude mice in Matrigel. Cancer Res 1991; 51: 3814-27.

23 Pretlow TG, Wolman SR, Micale MA, Pelley RJ, Kursh ED, et al. Xenografts of primary human prostatic carcinoma. J Natl Cancer Inst 1993; 85: 394-408.

24 van Weerden WM, van Kreuningen A, Elissen NMJ, Vermeij M, de Jong FH, et al. Castration-induced changes in morphology, androgen levels, and proliferative activity of human prostate cancer tissue grown in athymic nude mice. Prostate 1993; 23: 149-64.

25 de Pinieux G, Legrier LM, Poirson-Bichat F, Courty Y, BrasGoncalves R, et al. Clinical and experimental progression of a new model of human prostate cancer and therapeutic approach. Am J Pathol 2001; 159: 753-64.

26 Gray DR, Huss WJ, Yau JM, Durham LE, Werdin ES, et al. Short-term human primary xenografts: an in vivo model of human prostate cancer vasculature and angiogenesis. Cancer Res 2004; 64: 1712-21.

27 Huss WJ, Gray DR, Werdin ES, Funkhouser Jr WK, Smith GJ. Evidence of pluripotent human prostate stem cells in a human prostate primary xenograft model. Prostate 2004; 60: 77-90.

28 McCulloch DR, Opeskin K, Thompson EW, Williams EW. BM18: A novel androgen-dependent human prostate cancer xenograft model derived from a bone metastasis. Prostate 2005; 65: 35-43.

29 Wang Y, Revelo MP, Sudilovsky D, Cao M, Chen WG, et al. Development and characterization of efficient xenograft models for benign and malignant human prostate tissue. Prostate 2005; 64: 149-59.

30 Schroeder FH, Okada K, Jellinhaus W, Wullstein HK, Heinemeyer HM. Human prostatic adenoma and carcinoma. Transplantation of cultured cells and primary tissue fragments in nude mice. Invest Urol 1976: 13: 395-403.

31 Reid L, Sato G. Development of transplantable tumors of human prostate gland implanted in nude mice. J Cell Biol 1976; 70: 860a.

32 Presnel SC, Werdin ES, Maygarden S, Mohler JL, Smith GJ. Establishment of short-term primary human prostate xenografts for the study of prostate biology and cancer. Am J Pathol 2001; 159: 855-70.

33 Lubaroff DM, Cohen MB, Schultz LD, Beamer WG. Survival of human prostate carcinoma, benign hyperplastic prostate tissues, and IL-2-activated lymphocytes in scid mice. Prostate 1995; 27: 32-41.
34 Kleinman HK, McGarvey ML, Liotta LA, Robey PG, Tryggvason $\mathrm{K}$, et al. Isolation and characterization of type IV procollagen, laminin, and heparan sulfate proteoglycan from the EHS sarcoma. Biochemistry 1982; 21: 6188-93.

35 Reid LCM, Shin S. Transplantation of heterologus endocrine tumor cells in nude mice. In: Fogh J, Giovanella BC, editors. The Nude Mouse in Experimental and Clinical Research. New York: New York Academic Press; 1978. p313-51.

36 Hoehn W, Wagner M, Riemann JF, Hermanek P, Williams $\mathrm{E}$, et al. Prostatic adenocarcinoma PC EW, a new human tumor line transplantable in nude mice. Prostate 1984; 5: 445-52.

37 van Weerden WM, de Ridder CM, Verdaasdonk CL, Romijn JC, van der Kwast TH, et al. Development of seven new human prostate tumor xenografts models and their histopathological characterization. Am J Pathol 1996; 149: 1055-62.

38 Rubin MA, Putzi M, Mucci N, Smith DC, Wojno K, et al. Rapid (warm) autopsy study for procurement of metastatic prostate cancer. Clin Cancer Res 2000; 6: 1038-45.

39 Yoshida T, Kinoshita H, Segawa T, Nakamura E, Inoue T, et al. Antiandrogen bicatulamide promotes tumor growth in a novel androgen-dependent prostate xenograft model derived from a bicatulamide-treated patient. Cancer Res 2005: 65: 9611-6.

40 van Haaften-Day C, Raghavan D, Russell P, Wills EJ, Gregory $\mathrm{P}$, et al. Xenografted small cell undifferentiated cancer of prostate: possible common origin with prostatic adenocarcinoma. Prostate 1987; 11: 271-9.

41 Ellis WJ, Vessella RL, Buhler KR, Bladou F, True LD, et al. Characterization of a novel androgen-sensitive, prostatespecific antigen-producing prostatic carcinoma xenograft: LuCaP 23. Clin Cancer Res 1996: 2: 1039-48.

42 Baisch H, Otto U, Fack H. Growth of human prostate carcinomas with and without hormone alpha-dehydrotestosterone in nude mice. Eur Urol 1998; 34: 505-11.

43 Klein KA, Reiter RE, Redula J, Moradi H, Zhu XL, et al. Progression of metastatic human prostate cancer to androgen independence in immunodeficient SCID mice. Nat Med 1997; 3: 402-8.

44 Wakasugi H, Koyama K, Gyotoku M, Yoshimoto M, Hirohashi S, et al. Frequent development of murine T-cell lymphomas with TcR alpha/beta+, CD4-/8- phenotype after implantation of human inflammatory breast cancer cells in BALB/c nude mice. Jpn J Cancer Res 1995; 86: 1086-96.

45 National Cancer Institute Best Practices for Biospecimen Resources (NCI, NIH, Bethesda, Md, 2007); http://biospecimens. cancer.gov/global/pdfs/NCI_Best_Practices_060507.pdf.

46 Lopez-Barcons LA. Human benign prostatic hyperplasia heterotransplants as an experimental model. Asian J Androl 2010; 12: 157-63.

47 Nagabhushan M, Miller CM, Pretlow TP, Giaconia JM, Edgehouse NL, et al. CWR22: the first human prostate cancer xenograft with strongly androgen-dependent and relapsed strains both in vivo and in soft agar. Cancer Res 1996; 56: 3042-6.

48 Ito YZ, Nakazato Y. A new serially transplantable human 
prostatic cancer (Honda) in nude mice. J Urol 1984; 132: 384-7.

49 Buhler KR, Quinn J, Liu AY, Wang H, Ellis WJ, et al. LuCaP 35: an androgen inducible, prostate-specific antigen producing human prostate cancer xenograft. Proc Am Assoc Cancer Res 1997; 38: 1600.

50 Corey E, Quinn JE, Vessella RL. A novel method of generating prostate cancer metastases from orthotopic implants. Prostate 2003; 56: 110-4.

51 van Steenbrugger GJ, Groen M, Bolt-de Vries J, Romijn JC, Schroeder FH. Human prostate cancer (PC-82) in nude mice: a model to study androgen regulated tumor growth. In: EORTC genitourinary group monograph 2, Part A: therapeutic principles in metastatic prostatic cancer. New York: Alan R. Liss Inc.; 1985. p23-50.

52 Marques RB, van Weerden WM, Erkens-Schulze S, de Ridder $\mathrm{CM}$, Bangma $\mathrm{CH}$, et al. The human PC346 xenograft and cell line panel: a model system for prostate cancer progression. Eur Urol 2006; 49: 245-57.

53 Shimosato Y, Kameya T, Nagai T, Hirohashi S, Koide T, et al. Transplantation of human tumors in nude mice. J Natl Cancer Inst 1976; 56: 1251-60.

54 Harper ME, Goddard L, Smith C, Nicholson RI. Characterization of a transplantable hormone-responsive human prostatic cancer xenograft TEN12 and its androgenresistant sublines. Prostate 2004; 58: 13-22. 